\title{
Article \\ Determination of eleven veterinary drugs in chicken meat and liver
}

Cauê S. Novo ${ }^{1}$, Amanda Barros' ${ }^{1}$, Vivian Feddern',* ${ }^{2}$, Arlei Coldebella ${ }^{2}$ and Gerson N. Scheuermann²

1 Associação Brasileira de Proteína Animal, ABPA [Brazilian Association of Animal Protein], 1912 Brigadeiro Faria Lima Av., 01451-907 São Paulo/SP, Brazil; caue.s.novo@hotmail.com, amanda.barros@abpa-br.org

2 Embrapa Suínos e Aves [Embrapa Swine and Poultry], BR 153, km 110, 89715-899 Concórdia/SC, Brazil; vivian.feddern@embrapa.br, arlei.coldebella@embrapa.br, gerson.scheuermann@embrapa.br

* Correspondence: vivian.feddern@embrapa.br; Tel.: +55-49-34410400

\begin{abstract}
Brazil chicken production is around 13 million tons and about a third is exported to over 150 countries, placing Brazil as the world largest chicken meat producer, and therefore it is crucial to follow the legislation of all importer markets. This study aimed at evaluating ten chemical residues (amoxicillin, bacitracin, colistin, dinitolmide + zoalene, spectinomycin, roxarsone, tiamulin, tylosin, trenbolone acetate and virginiamycin) in chicken breast and one (halofuginone hydrobromide) in chicken liver. Most of these compounds are not covered by National Residues and Contaminants Control Plan (PNCRC), although they are mandatory to export chicken meat worldwide. A total of 2580 samples were collected from 45 industries and submitted to analyte extraction and chromatographic verification of compliance in an accredited laboratory. The results showed that no compound exceeded the maximum residue limits established by worldwide legislation. All results were below the method detection limit, thereby confirming the capability of Brazilian chicken meat plants in complying to foreign markets. Our results can provide occurrence trends of veterinary drug from poultry products in Brazil.
\end{abstract}

Keywords: broiler; feed additives; LC-MS; poultry meat; veterinary drugs

\section{Introduction}

Brazil is the world leader in chicken exports (4.2 million tons), serving more than 150 countries, followed by the United States (3.2 million tons) and the European Union (1.5 million tons). With respect to chicken production, Brazil also plays a significant role as and the second largest producer (13.2 million tons), being overcome by the United States (19.9 million of tons) and close to the European Union (12.4 million tons), occupying 13\% of the world market in chicken meat production [1].

Poultry products are among the main protein sources consumed in the world because they please people of any religion, are relatively cheap when compared to other meat sources and are versatile once they can be prepared in different ways and be part of many dishes. Considering that from the amount produced, $68 \%$ remains in the country and $32 \%$ is exported [1], it is necessary to keep monitoring the safety of poultry products to assure consumer protection, maintain the high quality of the food products, specially concerns related to sanitary and residue issues, as well as sensitiveness to specific requirements of different markets.

Regulatory agencies and authorities have established maximum residue limits (MRL) in various food matrices of animal origin to support governments and food operators in the monitoring of veterinary drug residues in the food chain. About 200 veterinary drug residues from several families, mainly with antibiotic, antiparasitic or anti-inflammatory activities, are regulated in a variety of food matrices [2]. As veterinary drugs and feed additives are used in animal husbandry, there are concerns about residues in edible matrices [3]. 
In this sense, exporter food companies must follow the rules of the importing countries. Such demands may be difficult to attend and depend on advanced laboratory techniques, such as liquid-chromatography coupled to mass spectrometry to detect extremely low amounts of a given veterinary drug. At the end, the objective is to demonstrate that an exporter country can produce meat in such required circumstances.

Therefore, it is important to continuously control and monitor the quality of chicken meat and products, investigating if the industry complies with the agreed international standards. Besides, it is recommended that the statistical reassessment of the National Sampling Plan undergoes a review, if necessary, to evaluate residues of some substances. Therefore, the objective of this study was to evaluate randomly 45 different Brazilian exporter chicken companies regarding eleven compounds normally used in the poultry production system and check whether residues of these chemicals are detected in concentrations above the legislation limits.

\section{Results and Discussion}

\subsection{Feed additives}

The use of feed additives or veterinary drugs may result in residue concentrations in edible tissues that exceed the corresponding maximum residue limits (MRL), therefore it is important to continuously monitor and control the presence of residues in the production chain to assure food security. From the evaluated veterinary drugs shown in Table 1, all complied to the international standards.

Regarding the domestic market, Brazilian MAPA monitors feed additives in different matrices (muscle, egg, kidney, milk, and honey) from animal-origin samples. Every year, MAPA collects samples from Federal Inspected (SIF) meat plants and monitors the feed additive residues through the National Plan for the Control of Residues and Contaminants in Animal Products (PNCRC) for the chains of beef, pork, goat, mutton, equine, rabbit, poultry, ostrich meat, and milk, fisheries, honey, and eggs. Usually, MAPA analyzes 7 from the 11 antimicrobials displayed in Table 1, however in a different matrix, other than chicken muscle, for instance, bacitracin in eggs or spectinomycin in kidneys. Nevertheless, when Brazil wants to export chicken meat to other countries, it must follow the rules of these countries and sometimes need to analyze other veterinary drugs in different matrices, as happened in the present research. For instance, Brazilian MAPA published an ordinance (87/2018) recognizing the private protocol of the Gulf Technical Regulation to attend Middle East requirements [5].

Among the chemical residues monitored in chicken meat production by Brazilian PNCRC (Table 1) which are demanded and analyzed by the main importing countries, most of them refer to antibiotics used as prophylactic agents. For instance, tylosin is a macrolide antibiotic, which is registered exclusively for veterinary use (pigs, chickens, turkeys, and cattle) in many countries and is effective against gram-positive bacteria, Mycoplasma and Chlamydia spp. Tylosin is available as a premix and as a powder to add to feed or to the drinking water [3].

Amoxicillin (AMX) is a semisynthetic $\beta$-lactam antibiotic which belongs to the aminopenicillin group. AMX has a broad antimicrobial spectrum, low toxicity when compared to other veterinary drugs and a relatively good absorption rate. It is of low cost and applied in poultry farming. However, it may penetrate in tissues and is considered in most monitoring plans in Latin America [6]. Colistin is one of the most effective antimicrobial agents and showed to inactivate Salmonella spp. in poultry by $100 \%$ [7].

Tiamulin is approved to be used in chicken and turkey to reduce the severity of disease caused by mycoplasma, while in swine, tiamulin is FDA-approved to treat pneumonia and dysentery [8]. Bacitracin is indicated for the prevention of necrotic enteritis caused, for instance, by Clostridium spp [9]. 
Spectinomycin is an aminocyclitol antibiotic, distinct from the aminoglycosides and has a broad-spectrum antibiotic applied in veterinary medicine for mycoplasma infections and for treating organisms with multiple antibiotic resistance $[10,11]$.

Roxarsone is an arsenic-basic veterinary drug, which was banned since 2014 and withdrawn from the market [12]. Although arsenic speciation is an important issue to be considered, once the organic form is less harmful than the inorganic one, FDA banned the commercialization [13]. Therefore, if this compound is found in feed or food matrices, it violates legislation, except for China and Asia, which accept this additive.

Virginiamycin is used as a feed additive to enhance growth of animals, such as cows, swine, poultry, and fish, and contains lactonic rings that are primarily composed of two anti-bacterial factors, namely M1 and S1 [14]. Only Codex forbids its use [15].

Halofuginone hydrobromide is an antiparasitic agent, which acts against protozoa [16], and is more common to be analyzed in liver, while trenbolone acetate is a synthetic progestational agent, used mainly as implants under the animal skin of feedlot steers [17]; and usually analyzed in cattle [15] in both muscle (MRL $=2 \mu \mathrm{g} / \mathrm{kg}$ ) and liver (MRL = 10 $\mu \mathrm{g} / \mathrm{kg}$ ); however anabolic steroids are forbidden for food producing animals in the EU [18], China [19], USA [20] and Brazil [21], although it stands in Brazilian legislation, the $\mathrm{MRL}=2 \mu \mathrm{g} / \mathrm{kg}$ (Table 1) corresponds to the Minimum Required Performance Limit (MRPL) for the analytical method in swine urine. Dinitolmide is a nitro amide coccidiostat used in poultry feed and may be harmful to the environment and human health [22] and it is not authorized in Brazil, EU and nor recommended by Codex $[15,16,21]$, however it is allowed by Canada, China, USA and Asian legislation at $3000 \mu \mathrm{g} / \mathrm{kg}$ (Table 1).

Although these three compounds mentioned above have MRL according to Brazilian legislation, they are not registered by MAPA; the country does not have validated methodologies to analyze them as a routine. Therefore, these analyses are performed by accredited laboratories, only when demanded by certain importing countries, whose headquarters lays abroad. To maintain the poultry production and exports, it is imperative to continuously educate farmers. This includes the introduction of chemical residue legislation to this public, besides knowledge about inspection system, biosecurity measures and animal vaccination, so as to ensure food safety, food security, and public health [23].

Table 1. Results of the eleven compounds analyzed in chicken meat and liver, number of samples analyzed for each matrix; Brazilian legislation (matrix, number of samples, MRL) compared to worldwide MRL legislation regarding these same residues in meat.

\begin{tabular}{|c|c|c|c|c|c|c|c|c|c|c|c|}
\hline \multicolumn{6}{|c|}{ This study } & \multicolumn{6}{|c|}{ MRL in meat $(\mu \mathrm{g} / \mathrm{kg})$} \\
\hline Compound & $\begin{array}{c}\text { Residues } \\
(\mu \mathrm{g} / \mathrm{kg}) *\end{array}$ & $\begin{array}{l}\text { Number of } \\
\text { samples ** }\end{array}$ & & Brazil a & & $\begin{array}{c}\text { Middle } \\
\text { East }^{\mathrm{b}}\end{array}$ & EUc & China $^{\mathrm{d}}$ & Canadae & USA $^{f}$ & CODEXg \\
\hline & & & Matrix & $\begin{array}{c}\text { Number } \\
\text { of samples }\end{array}$ & MRL & & & & & & \\
\hline Amoxicillin & $<10$ & 300 & $\begin{array}{c}\text { Chicken } \\
\text { muscle }\end{array}$ & 600 & 50 & 10 & 50 & 50 & 10 & 10 & 50 \\
\hline Bacitracin & $<75$ & 300 & Egg & 300 & 500 & 500 & 150 & 500 & 500 & 500 & - \\
\hline Colistin & $<75$ & 300 & Egg & 300 & 300 & 150 & 150 & 150 & - & - & 150 \\
\hline $\begin{array}{l}\text { Dinitolmide } \\
\text { and zoalene }\end{array}$ & $<5$ & 60 & - & - & - & 3000 & - & 3000 & 3000 & 3000 & - \\
\hline Spectinomycin & $<50$ & 300 & Kidney & 600 & 5000 & 100 & 300 & 500 & 100 & 100 & 500 \\
\hline $\begin{array}{l}\text { Halofuginone } \\
\text { hydrobromide }\end{array}$ & $<3$ & 60 & - & - & - & 100 & 10 & 10 & 10 & - & - \\
\hline Roxarsone & $<70$ & 300 & - & - & - & 500 & - & 500 & - & - & - \\
\hline Tiamulin & $<25$ & 300 & Egg & 300 & 1000 & 100 & 100 & 100 & 100 & - & - \\
\hline
\end{tabular}




\begin{tabular}{lccccccccccc}
\hline Tylosin & $<25$ & 300 & $* * *$ & 600 & 100 & 200 & 100 & 200 & 200 & 200 & 100 \\
\hline $\begin{array}{l}17-\alpha- \\
\text { Trenbolone }\end{array}$ & $<2$ & 60 & $\begin{array}{c}\text { Swine } \\
\text { urine }\end{array}$ & 60 & 2 & 2000 & - & - & 2 & - & 2 \\
\hline Virginiamycin & $<20$ & 300 & - & - & - & 200 & 10 & 100 & 100 & 100 & - \\
\hline
\end{tabular}

a BRASIL [21]; ${ }^{\mathrm{b}}$ Gulf Technical Regulation[25]; c UE[16]; d MOA[19]; e Health Canada [26]; ${ }^{\mathrm{C}}$ Code of Federal Regulation [20]; g Codex Alimentarius [15]

${ }^{*}$ Residue found were below the MRL comparing all worldwide legislation; **all samples evaluated herein were from chicken breast, except for halofuginone hydrobromide, which was analyzed in liver; ***Tylosin has MRL for chicken muscle, kidney, egg, milk, and honey

2.2. Statistical analyses to evaluate the need of decreasing the National sampling plan and increasing limit of non-compliance

For a $95 \%$ probability of detecting a violation, if it occurs in $1 \%$ of the population, the event should be surveyed in 299 individuals and/or units of that population, a number that is rounded to 300, for practical purposes as recommended by MAPA [24]. This minimum amount is important for the establishment of plans/protocols that are being implemented for the first time and whenever necessary, the sampling plan can be revised.

Therefore, considering these satisfactory results and that more analyzes of each substance are carried out annually, making the Brazilian protocol increasingly robust, it is possible to increase the prevalence limit for non-compliance from $1.0 \%$ to $1.5 \%$ for the substances allowed for use in national poultry farming. In this situation, the sampling calculated by the binomial model to guarantee (with $95 \%$ confidence) that there would be at least one sample above the MRL would be 199 per year, rounded up to 204 samples for convenience, representing 17 monthly samples. For substances not allowed for use in poultry farming, sampling must be maintained according to the protocol in execution.

\section{Materials and Methods}

\subsection{Sampling plan and chromatographic determination of chemical residues}

A total of 2580 chicken meat and liver samples were collected (Figure 1) during one year of evaluation (March 2019 to March 2020) from 45 slaughterhouses registered under the Federal Inspection System (SIF), which are licensed to export to foreign markets, allowed by the Brazilian Ministry of Agriculture, Livestock and Food Supply (MAPA).

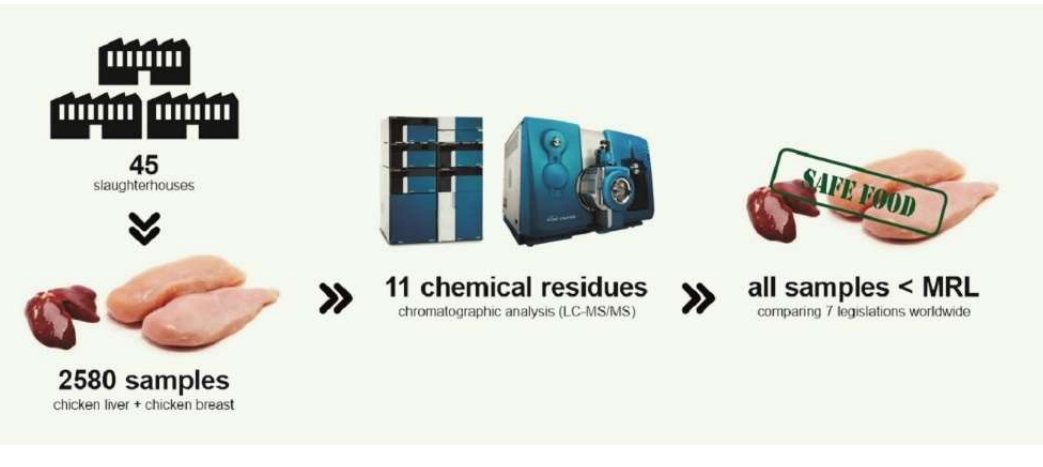

Figure 1. Chicken sample collection and determination according to official procedures

In the sampling plan proposed and executed in the protocol, the prevalence of nonconformity of $1 \%$ and $95 \%$ confidence coefficient for substances allowed for use in national poultry farming was considered, totaling an annual sampling of 300 samples for each substance. For three compounds (dinitolmide, halofuginone hydrobromide and trenbolone acetate) not registered by MAPA for use in poultry production, a higher prevalence of 
non-conformity (5\%) was considered, resulting in 60 samples annually, at $95 \%$ confidence coefficient.

The samples were immediately identified, processed, and submitted to an accredited laboratory, Eurofins, located in Indaiatuba, SP, Brazil. The sample preparation procedure comprised homogenization and solid-liquid extraction with acetonitrile. Then the samples were submitted to the dilution and filtration process, ready for subsequent chromatographic analysis, according to an internal protocol of the laboratory: Internal Method POP-QV028/3 for tiamulin, virginiamycin, tylosin, spectinomycin, amoxicillin, trenbolone acetate, dinitolmide+zoalene; Internal Method POP-QV013/3 for bacitracin, colistin, halofuginone hydrobromide; and AOAC 2013.06 for roxarsone.

In order to determine the chemical residues by chromatographic analysis, a C8 column (150 mm x $3 \mathrm{~mm} \times 4 \mu \mathrm{m})$ was used for analytes separation in a system consisting of an HPLC (Sciex Exion LC), coupled to an ABSciex API 5500 mass detector, with a binary pump, a column oven, and an auto-injector. The mobile phase consisted of an aqueous solution with $0.1 \%$ formic acid $(\mathrm{v} / \mathrm{v})+5 \mathrm{mM}$ ammonium formate and methanol with $0.1 \%$ formic acid $(\mathrm{v} / \mathrm{v})+5 \mathrm{mM}$ ammonium formats.

\subsection{Statistical analysis}

The sampling procedures are specific to each type of problem to be addressed. With respect to the National Residues and Contaminants Control Plan (PNCRC) applied to products of animal origin, Discrete Probability Models are usually adopted. The main discrete models used in the PNCRC are based on the Hypergeometric and Binomial Distribution Models.

The Hypergeometric Model aims to describe the number of successes (for example, a sample violating the MRL of a given residue displayed at the PNCRC) in a sequence of " $n$ " extractions from a finite population of small size, without replacement. In this case, the effect of sampling without replacement significantly impacts in the coming probabilities of a new successful sample. For this situation, the sample distribution must be based on the Hypergeometric Distribution.

In populations of larger sizes ( $>$ 5,000 units evaluated, for instance), the effect of sampling without replacement is negligible. Thus, the Binomial Distribution can be used to determine an appropriate number of samples to be used, as the number of samples for a high confidence coefficient defined previously, will be constant for populations over 5,000 evaluated units [4]. PNCRC for poultry, swine, and cattle (and other species) fall into this category, given the number of animals normally slaughtered over the period of one year.

For adoption of the Binomial Distribution Model, initially a certain residue/contaminant is quantified in a particular number of samples and, subsequently, each sample is classified as a Binary Variable as: $0=$ does not violate the MRL for market " $\mathrm{X}$ " or 1 = violates the MRLs for the same " $X$ " market. Thus, each sample behaves like a success and failure test, characterized as a classic Bernoulli distribution model, the sum of "N" Bernoulli tests, originating the Binomial Probability Distribution. Thus, the Binomial model is more likely to be suitable for PNCRC because the populations of interest (cattle, poultry, swine, etc.) consist of thousands of individuals and/or units.

When non-compliance results are detected (for example, MRL violations of a given residue " $\mathrm{X}$ "), it is possible to obtain an estimate of likely prevalence of each residue in the general population. However, when non-compliant results are not found or the behavior of residue " $\mathrm{X}$ " is unknown, as is the case for some residues not yet assessed by the PNCRC, any claims about prevalence should be stated with a defined confidence coefficient, so that the prevalence of non-compliant results does not exceed a specified percentage. In this case, a prevalence of $1 \%$ is usually adopted when the behavior of residue " $\mathrm{X}$ " is unknown. The number of samples needed to provide a high coefficient of confidence to detect at least one non-conformity result is around 300 samples [4].

\section{Conclusions}


None of the evaluated substances as residue in the Brazilian chicken meat does violate any of the international regulatory limits considered (Middle East, EU, China, Canada, USA, CODEX). Whether good manufacturing practices and good production practices are adopted, the risk of chemical residues in products of animal origin are minimized. Even so, a continuous, broad, and robust monitoring plan cannot be ignored to maintain the quality, safety, and competitiveness, of the meat products.

Author Contributions: Conceptualization C.S.N., A.B., G.N.S.; project administration A.B., G.N.S.; Resources A.B., G.N.S.; methodology and investigation C.S.N., A.C., G.N.S.; data curation, formal analysis, software and supervision A.C.; writing-original draft V.F.; writing-review \& editing C.S.N., A.B., V.F., A.C., G.N.S. All authors have read and agreed to the published version of the manuscript

Funding: This research was funded by ABPA.

Acknowledgments: To all coworkers and associates from ABPA for their support during the development of the research; to Marina Schmitt from Embrapa, for designing Figure 1.

Conflicts of Interest: The authors declare no conflicts of interest.

\section{References}

1. ABPA Relatório Anual Available online: http://abpa-br.org/relatorios/ (accessed on Aug 31, 2020).

2. Delatour, T.; Racault, L.; Bessaire, T.; Desmarchelier, A. Screening of veterinary drug residues in food by LC-MS/MS. Background and challenges. Food Addit. Contam. Part A 2018, 35, 632-645, doi:10.1080/19440049.2018.1426890.

3. Vandenberge, V.; Delezie, E.; Delahaut, P.; Pierret, G.; de Backer, P.; Daeseleire, E.; Croubels, S. Transfer of flubendazole and tylosin from feed at cross-contamination levels to various poultry matrices. Poult. Sci. 2012, 91, 2351-2360, doi:10.3382/ps.2012-02265.

4. CODEX ALIMENTARIUS CAC/GL 71-2009: Guidelines for the design and implementation of national regulatory food safety assurance programmes associated with the use of veterinary drugs in food producing animals. Adopted 2009. Rev. 2012,2014 Available online: http://www.fao.org/fao-who-codexalimentarius/codex-texts/guidelines/en/ (accessed on Oct 15, 2020).

5. BRASIL Ordinance $n^{\circ}$ 87, of August 16, 2018; 2018;

6. Ledesma, C.; Rosario, C.; Gracia-Mora, J.; Tapia, G.; Gutiérrez, L.; Sumano, H. Antibacterial activity of amoxicillin in vitro and its oral bioavailability in broiler chickens under the influence of 3 water sanitizers. Poult. Sci. 2018, 97, 2391-2399, doi:10.3382/ps/pey114.

7. Singh, R.; Yadav, A.S.; Tripathi, V.; Singh, R.P. Antimicrobial resistance profile of Salmonella present in poultry andpoultry environment in north India. Food Control 2013, 33, 545-548, doi:10.1016/j.foodcont.2013.03.041.

8. Plumb, D.C. Plumb's Veterinary Drug Handbook; 9th ed.; PharmaVet Inc.; Wiley-Blackwell: Hoboken, New Jersey, 2018; ISBN 978-1-119-34445-2.

9. $\quad$ Krueger, L.A.; Spangler, D.A.; Vandermyde, D.R.; Sims, M.D.; Ayangbile, G.A. Avi-Lution ${ }^{\circledR}$ supplemented at 1.0 or 2.0 g/kg in feed improves the growth performance of broiler chickens during challenge with bacitracin-resistant Clostridium perfringens. Poult. Sci. 2017, 96, 2595-2600, doi:10.3382/ps/pex074.

10. The International Encyclopedia of Adverse Drug Reactions and Interactions Spectinomycin. In Meyler's Side Effects of Drugs; Elsevier, 2016; p. 469.

11. Haagsna, N.; Scherpenisse, P.; Simmonds, R.J.; Wood, S.A.; Rees, S.A. High-performance liquid chromatographic determination of spectinomycin in swine, calf and chicken plasma using post-column derivatization. J. Chromatogr. B Biomed. Sci. Appl. 1995, 672, 165-171, doi:10.1016/0378-4347(95)00211-Z.

12. FDA Arsenic-based Animal Drugs and Poultry. Content current as of: 07/31/2019 Available online: https://www.fda.gov/animal-veterinary/product-safety-information/arsenic-based-animal-drugs-and-poultry (accessed on Dec 2, 2020).

13. Kawalek, J.C.; Carson, M.; Conklin, S.; Lancaster, V.; Howard, K.; Ward, J.; Farrell, D.; Myers, M.; Swain, H.; Jeanettes, P.; et 
al. Final Report on Study 275.30. Provide Data on Various Arsenic Species Present in Broilers Treated with Roxarsone: Comparison with Untreated Birds. FDA 2011, 2013.

14. Wang, X.; Wang, M.; Zhang, K.; Hou, T.; Zhang, L.; Fei, C.; Xue, F.; Hang, T. Determination of virginiamycin M1 residue in tissues of swine and chicken by ultra-performance liquid chromatography tandem mass spectrometry. Food Chem. 2018, 250, 127-133, doi:10.1016/j.foodchem.2018.01.024.

15. Codex Alimentarius Maximum residue limits (MRLs) and risk management recommendations (RMRs) for residues of veterinary drugs in food CX/MRL 2-2018 Available online: http://www.fao.org/fao-who-codexalimentarius/codextexts/dbs/vetdrugs/veterinary-drugs/en/ (accessed on Dec 3, 2020).

16. UE COMMISSION REGULATION (EU) No 37/2010 of 22 December 2009 on pharmacologically active substances and their classification regarding maximum residue limits in foodstuffs of animal origin. Off. J. Eur. Union 2010, 1, 1-72.

17. Ribeiro, G.O.; May, M.L.; Parr, S.L.; Schunicht, O.C.; Burciaga-Robles, L.O.; Hannon, S.J.; Grimson, T.M.; Booker, C.W.; McAllister, T.A. Effects of conventional and nonconventional growth-enhancing technologies for finishing feedlot beef steers. Appl. Anim. Sci. 2020, 36, 524-536, doi:10.15232/aas.2019-01962.

18. Becker, C.; Riedmaier, I.; Reiter, M.; Tichopad, A.; Pfaffl, M.W.; Meyer, H.H.D. Effect of trenbolone acetate plus estradiol on transcriptional regulation of metabolism pathways in bovine liver. Horm. Mol. Biol. Clin. Investig. 2010, 2, doi:10.1515/hmbci.2010.029.

19. MOA National Standard No. 235. 2002. Available online: http://english.agri.gov.cn (accessed on Dec 3, 2020).

20. Code of Federal Regulation Title 21 - Food and Drugs. Chapter I - Food and Drug Administration, Department of Health and Human services. Subchapter E - animal drugs, feeds, and related products part 556 - tolerances for residues of new animal drugs in food Available online: https:/www.govinfo.gov/content/pkg/CFR-2020-title21-vol6/pdf/CFR-2020-title21-vol6chapI-subchapE.pdf (accessed on Dec 3, 2020).

21. BRASIL Sampling plan for the meat chains. Brazilian National plan for the control of residues and contaminants (PNCRC). Normative Instruction no 5 of April 23, 2019 (Published in the Official Gazette of the Federal Government (DOU) on 25/04/2019). Available online: https://www.gov.br/agricultura/pt-br/assuntos/inspecao/produtos-animal/plano-de-nacionalde-controle-de-residuos-e-contaminantes/PNCRC2019SamplingPlan.pdf (accessed on Aug 31, 2020).

22. Liu, J.; Song, S.; Wu, A.; Wu, X.; Xiao, J.; Xu, C. Development of a gold nanoparticle-based lateral-flow strip for the detection of dinitolmide in chicken tissue. Anal. Methods 2020, 12, 3210-3217, doi:10.1039/D0AY00885K.

23. Alhaji, N.B.; Haruna, A.E.; Muhammad, B.; Lawan, M.K.; Isola, T.O. Antimicrobials usage assessments in commercial poultry and local birds in North-central Nigeria: Associated pathways and factors for resistance emergence and spread. Prev. Vet. Med. 2018, 154, 139-147, doi:10.1016/j.prevetmed.2018.04.001.

24. BRASIL Instrução Normativa SDA No 42 de 20 de dezembro de 1999. Plano Nacional de Controle de Resíduos em Produtos de Origem Animal (PNCRC/Animal) Available online: https://www.gov.br/agricultura/pt-br/assuntos/inspecao/produtosanimal/plano-de-nacional-de-controle-de-residuos-e-contaminantes/documentos-da-pncrc/instrucao-normativa-sda-n-o-42de-20-de-dezembro-de-1999.pdf/@@download/file/instrucao-normativa-sda-n-o-4 (accessed on Dec 3, 2020).

25. Gulf Technical Regulation Maximum Residues Limits (MRLs) of veterinary drugs in Food Available online: https://www2.sag.gob.cl/pecuaria/establecimientos_habilitados_exportar/normativa/EAU/GSO-2481-2015-en.pdf (accessed on Dec 3, 2020).

26. Health Canada $[\mathrm{HC}]$ List of maximum residue limits (MRLs) for veterinary drugs in foods Available online: https://www.canada.ca/en/health-canada/services/drugs-health-products/veterinary-drugs/maximum-residue-limitsmrls/list-maximum-residue-limits-mrls-veterinary-drugs-foods.html (accessed on Dec 3, 2020). 